\title{
Entrevista con Margo Glantz: una Literatura Irreverente
}

Interview with Margo Glantz: an Irreverent Literature

Fernanda Lobo

Recebido em: 17 de asosto de 2020

Aceito em: 20 de agosto de 2020
Fernanda Lobo é mestra em Letras, com habilitação em Espanhol pela Universidade de São Paulo. Foi bolsista CAPES na pesquisa de pós-graduação em literatura latino-americana, além de atuar no mercado editorial como editora e tradutora do Espanhol.

Contato: fernanda.neveslobo@ smail.com

Brasil 
La presente entrevista con la escritora mexicana fue realizada a fines de 2018 en la Ciudad de México, cuando pasé allí un año realizando un intercambio durante mi investigación de maestría, en la que estudié Historia de una mujer con zapatos de diseñador, publicado por la editorial Anagrama en 2005. En ese momento, sólo circulaba en Brasil su novela Apariçôes, publicada por la editorial Autêntica, y en traducción de Paloma Vidal, quien también tradujo E por olhar tudo, nada via (2018), que fue editada en 2020 por la editorial Relicário.

\section{EL CUERPO MARGINADO}

Fernanda Lobo: Cuando pensamos en los escritores mexicanos de su generación, usted emerge como una figura disonante entre sus contemporáneos y su literatura se aparta tanto de la producción de estos escritores como de las líneas canónicas o más reconocibles de la literatura mexicana. ¿Cómo piensa usted dentro de ese contexto? Es decir: ¿Qué fue lo que posibilitó esa diferenciación?

Margo Glantz: Sí, yo, de alguna manera tuve muchas dificultades para publicar en el comienzo, porque lo que yo publicaba no estaba de acuerdo con lo que, en el momento, se publicaba. Entonces, me costó trabajo publicar mis primeros libros. Y, en realidad, empecé a escribir ficción un poco tarde, porque el tipo de ficción que yo cultivaba no era apreciada y no me la aceptaban. 
F.L.: Claro, por ejemplo, usted percibió muy temprano el tema del cuerpo en sus estudios, tema que hoy está muy presente en el arte en general, sobre todo en relación a las corporalidades marginadas. ¿Por qué cree que ese tema está tan presente en este momento?

M.G.: El cuerpo, para mí, fue, desde que yo era muy niña, un problema fundamental. Desde que yo leía - desde muy jovencita leí mucho, desde muy muy adolescente, desde los nueve, diez años leía ya bastante y, como adolescente, muchísimo -, una de las cosas que siempre me preocupaban al leer era la relación que había en los textos que leía con el cuerpo de la mujer. Cómo se veía el cuerpo de la mujer en Balzac, Stendhal, Dostoievski, las "novelas rosa”, que leía también en aquella época, o Julio Verne, donde la mujer está bastante ausente; en fin, para mí era muy importante.

Desde que empecé a dar clases, en 1958, el tema del cuerpo era muy importante en mis clases y en mis ensayos. Por ejemplo, me interesaba cómo se veía el cuerpo en la novela mexicana del siglo XIX y tengo un texto sobre el pie, que trata de un escritor mexicano de este mismo siglo, que se llama Tomás de Cuellar, "De pie sobre la literatura mexicana", que es de mucho antes de este en que estás trabajando [Historia de una mujer que caminó por la vida con zapatos de diseñador, 2005].

Es decir que siempre trabajé [el cuerpo]. Por ejemplo, en Santa, de Federico Gamboa, era fundamental porque era una prostituta y ese es el tema más importante de la vida de una prostituta. Entonces, Los bandidos de Río Frío, cómo se veía el cuerpo de las mujeres, cómo no se escribía el cuerpo de los 
hombres, pero el de las mujeres se lo escribía. O cómo, por ejemplo, en una novela romántica como María de Jorge Isaacs, este cuerpo de las mujeres de las altas clases no se lo escribía, apenas la cintura y las trenzas, en cambio, de la mulata, por la que Efraín de Jorge Isaacs tenía un deseo sexual encubierto, la describe completita. Todo ese tipo de cosa, como la relación de cuerpo y clase, lo trabajé mucho, hace muchísimos años...

F.L.: Sí, que las mujeres de clases más altas son sacralizadas y las de clases más bajas son...

M.G.: Exactamente. María, que es la novia santa de la novela más importante, la novela romántica más importante de Latinoamérica de la que todo el mundo habla. Había escritores mexicanos que decían que ya, al leerla llorábamos, que es una novela húmeda, todo el mundo llora. Entonces, el cuerpo de María era un cuerpo casi intangible. Cuando muere ella, lo único que le queda del cuerpo a Efraín son sus trenzas, que guarda. O sea, las trenzas son un elemento de erotismo muy importante, pero que, al mismo tiempo, está muy soslayado. Yo también escribí un libro sobre el pelo y ahora se acaba de reeditar [De la amorosa inclinación a enredarse en cabellos, primera edición de 1984], en donde trabajo la importancia del pelo como elemento erótico y al mismo tiempo tan tanático. Del cuerpo es uno de los elementos que sobreviven a la muerte, las uñas y el pelo se mantienen como imperecederos de alguna forma. Hay cadáveres que llevan pelo mismo después de mucho tiempo de muertos. Pero el pelo es un elemento del erotismo que es cubierto dentro de los fundamentalismos. Las 
musulmanas no pueden enseńar el cabello, las judías fundamentalistas, religiosas, usan la peluca, solo su marido le puede ver el pelo. Entonces, cuando uno lee los romances castellanos aparecen mujeres con el pelo suelto y eso ya incita al erotismo inmediatamente, por lo que, a mí, me pareció muy importante establecer las relaciones que existían entre cuerpo y erotismo, entre cuerpo y sociedad, entre cuerpo y represión etc...

Me interesaba analizar cómo el cuerpo de la mujer ha sido siempre un objeto de cancelación, es decir, la tentación, el pelo, los senos, los brazos y cada cultura cancela una parte del cuerpo. Las indias, por ejemplo, pueden enseñar el estómago, pero no pueden enseñar los brazos. En la época de los siglos de oro en España, las mujeres no podían enseñar los pies, usaban una especie de resorte en la falda, que se llamaba tontillo, que cuando se sentaban les tapaba los pies. Era un resorte que les tapaba los pies porque eran un símbolo de erotismo, en consecuencia, una forma de provocar. Siempre la mujer provocando. Es así que el cuerpo de la mujer siempre ha sido vetado por partes, entonces yo trabajo mucho la cosa de la fragmentación.

F.L.: ¿Por qué el tema del cuerpo vuelve ahora?

M.G.: Estamos en un período muy complicado, me parece. Por un lado, hay una aparente liberación, por medio de lo que fue el movimiento \#metoo y sus desdoblamientos, en que la mujer defiende la posibilidad de exhibir su cuerpo o de tenerlo para ella sin que sufra el acoso masculino, la necesidad de que la mujer obtenga todos los derechos de igualdad y las posibilidades de ser un 
ser humano igual que los hombres. Sin embargo, al mismo tiempo crecen los fascismos y los fascismos inmediatamente controlan el cuerpo de la mujer. Simone de Beauvoir decía que, en cuanto hay un cambio político o cultural, lo primero que se ataca son las mujeres. Ahora estamos debatiendo el tema del aborto y, en Brasil, es muy grave. En Brasil, donde el cuerpo es un tema fundamental - el carnaval exhibe el cuerpo impresionantemente -, tenemos a los evangélicos que ves en las fotografías de las nenas con carteles de "Con la Biblia basta, no es necesario aprender”, lo que a mí me parece asustador.

\section{LENGUAJE FRAGMENTADO Y REDES SOCIALES}

F.L.: Usted señaló que su literatura recurre constantemente al fragmento. Por su parte, Georges Bataille, cuya obra usted conoce muy bien e incluso ha traducido, dice, en El culpable : “...aunque sólo existe un mundo inacabado, cada una de sus partes no tiene menos sentido que el conjunto”. ¿De alguna manera el fragmento favorece el tipo de literatura que usted escribe? ¿Y, en ese sentido, qué papel jugaría la idea de totalidad dentro de su poética?

M.G.: Bataille, por ejemplo, tiene uno de los textos más hermosos que yo he leído. Está en Documentos, "El dedo gordo del pie”. Es el fragmento del fragmento del fragmento. Yo trabajo el pie completo, él trabaja el dedo gordo del pie. Y es algo realmente extraordinario. Y cuando Barthes hace un análisis

$1 \quad 2^{\text {a ed., Gallimard, }}$ 1961, 35 
de Bataille, trabaja ese texto y es un texto tan extraordinario como el de Bataille. O sea, son textos que me fascinan y son textos sobre el fragmento. Otro gran escritor francés que frecuento mucho es Pascal Quignard, que habla constantemente sobre el fragmento y tiene un libro que se llama Una molestia frente al cultivo del fragmento en la literatura [Une gêne technique à l'égard des fragments ${ }^{2}$ ], algo así, el título no lo sé bien de memoria, pero trabaja a un escritor del siglo XVII, que se llama La Bruyère, que escribía textos al revés, a los que les decían "maximes", porque eran todas máximas, que son fragmentos, algo que es absolutamente tradicional en la literatura, como también el haiku, o los aforismos, que es una forma cultivada clásicamente en todas las culturas y, sin embargo, la gente se asombra de que la gente frecuente el fragmento y, a mí, a mí me fascina mucho el fragmento.

Yo no sé si Bataille tenía una nostalgia de la completud, no, pero él lo trabaja muchísimo. Cuando hace un análisis de las flores, no trabaja los pétalos, no trabaja el aroma, sino que hace un análisis de los órganos reproductores de las flores en ese libro llamado Documento o, por ejemplo, trabaja los ojos y su libro se llama Historia del ojo. O sea, tiene nostalgia probablemente de lo completo, sin embargo, favorece lo incompleto y lo fragmenta.

Y yo también trabajaba mucho eso en muchos libros míos. Tanto en mis ensayos como en los de ficción, el fragmento ocupa un lugar muy importante y cada vez es más fragmentaria mi escritura. El mundo se está fragmentando cada vez más y más terriblemente, y la nostalgia de la totalidad nos lleva a 
totalitarismos, a fascismos. Entonces es una de las cosas que me parecen más graves. Por eso, yo creo que el fragmento es libertario frente a la totalidad que es totalitarismo.

F.L.: Sí, es la aceptación de muchas perspectivas. Y a mí, me parece que las múltiples perspectivas también tienen que ver con la desjerarquización de los temas. Está el tema de la profusión de informaciones en las redes sociales y a través de ellas. En algunos momentos, usted ya criticó a los intelectuales de su generación por no interactuar con este mundo virtual como usted hace twitteando y facebookeando usualmente. ¿Ve cómo incongruente que alguien cuelgue de la red fotografías de gatitos y también de asesinatos por parte del Estado en la misma línea del tiempo? ¿O, por el contrario, piensa que la red es una extensión de la simultaneidad de la vida?

M.G.: Yo pienso que las redes sociales fueron muy importantes y siguen siendo importantes como medios de comunicación y en muchos sentidos de liberación. Pero el sistema tiene muy bien sintonizadas las antenas para percibir de qué medios se pueden valer para poder mantener patrones totalitarios. Las redes han sido totalmente nocivas. Yo las sigo frecuentando porque pueden ser muy útiles para difundir información. Para mí, funcionan para poder expresar cosas que son muy fragmentarias, muy evanescentes, que de otra manera no puedo yo decir. Pero, por otro lado, siento que la comunicación se fortalece, hay una posibilidad de interacción. 
En Facebook, uno puede encontrar gente que ha perdido, demostrar cómo la intimidad se vuelve fundamental pero exhibida al mismo tiempo, toda una serie de problemas que afectan a la sociedad contemporánea y que se ventilan a través de las redes sociales. El hecho de que no se ha jerarquizado en absoluto, como el ejemplo que tu diste, determina que en el mismo nivel aparezca lo más siniestro y lo más elemental, lo más banal y que la gente pierda la capacidad de jerarquizar. Es por eso que hice este libro [ $Y$ por mirarlo todo nada veía, 2018].

Jerarquizar el pensamiento, escoger lo más importante ha sido siempre difícil, es de los problemas más importantes del mundo. El hecho de que las redes sociales aplanen todo $\mathrm{y}$, al mismo tiempo, nos bombardeen con una cantidad de noticias que son tan fugaces que no tenemos tiempo de retenerlas. Perdemos la capacidad de jerarquizar. Y eso es un problema muy importante de las sociedades contemporáneas y que las redes favorecen. Y, de alguna manera, favorecen propósitos políticos del sistema, que se está dando cuenta que estamos en una época en que la gente es absolutamente desechable. Ya era desechable con los campos de concentración, pero ahora con la robótica, con los clones, con todo eso, somos cada vez más desechables. Cada vez será mucho más fácil sustituir el trabajo humano. Entonces, de alguna manera, es como si [el sistema] quisiera hacer que las masas se conviertan en masas amorfas, sin educación, que puedan ser manejadas como le dé la gana. Ya ha habido muchísimos intentos de explicarlo en la época de los fascismos. Estamos en una época en que vuelven a aparecer los elementos y síntomas que eran visibles antes del nazismo. Por ejemplo, hay un libro 
muy importante de teoría que salió durante el nazismo, que fue Masa y poder, de [Elias] Canetti: habla de eso, de la masa. Y es muy importante para entender el nazismo. También hay el libro de Hannah Arendt, Los origenes del totalitarismo. Son libros que la gente ya no conoce y que son fundamentales para entender el mundo contemporáneo. Tenemos que tratar de trabajarlos, es decir, retrabajar a Hannah Arendt, retrabajar a Canetti, a Primo Levi. Por ejemplo, Jean Amery, que fue un austríaco judío, que estuvo en Auschwitz y que escribió libros muy muy importantes sobre la tortura y sobre el nazismo. Esta clase de libro es absolutamente actual, sin embargo, cada vez los conocemos menos. Los jóvenes no tienen la menor idea de qué son. Y en países en que los fascismos se aceleran, la educación anula la Historia desde la escuela primaria, se cancela la memoria. Estamos en un momento muy peligroso.

\section{LA LITERATURA Y SU RESPONSABILIDAD ÉTICA}

F.L.: Esa recuperación de autores, como Hannah Arendt, Primo Levi, Elias Canetti presupone una responsabilidad ética con la cual nosotros, los profesores, deberíamos comprometernos. En ese sentido, ¿Cómo usted piensa en el cruce de su actividad como crítica literaria, como escritora, como docente, una profesión que ejerció durante más de sesenta años? ¿Cree que hay una implicación ética en la enseńanza y en las otras funciones que usted desarrolla en el contexto de un mundo sin jerarquización, donde todo da lo mismo? 
M.G.: A mí, no me gusta dar mensajes, porque se confunden mucho con una visión muy tacaña de la vida, ¿no? Como cuando preguntan: “¿Qué mensaje va a dar usted a los jóvenes?” El único mensaje que puedo darles a los jóvenes es que sepan discernir. Por eso le puse de nombre a mi libro Y por mirarlo todo nada veía, un verso de Sor Juana Inés de La Cruz, que es parte de su poema fundamental Primero sueño: "Y por mirarlo todo nada veía, ni discernir podía”. Entonces, lo que más importa es que la gente aprenda a discernir, a entender, a jerarquizar, a ironizar. Hoy hay una literalidad impresionante en relación a lo que se lee. Por mi parte, yo trabajo muchísimo a los autores, tratando de encontrar cuáles son los resortes que el propio autor no encontró, que no sabía completamente cuando escribía, pero que eran metafóricos. Era una metáfora lo que él escribía, cuyo significado no desentrañaba exactamente pero se daba cuenta de las cosas. El que lee es quien tiene que desentrañar esa metáfora, qué significa. Por eso, creo que el papel del profesor es muy importante, muy creativo. Pienso que es muy importante que no sea mecánico ni automático al trabajar. Yo trabajo muy profundamente los textos en mis clases y aprendemos mucho, tanto los alumnos como yo. Vamos viendo, porque los alumnos tienen ojos nuevos, yo tengo ojos viejos, tengo ojos de experiencia, por lo que esa combinación entre la experiencia y la espontaneidad de la juventud ayuda muchísimo y creo que es de las cosas más importantes cuando uno enseña. 
Cuerpo en desplazamiento: Historia de una mujer...

F.L.: ¡Qué hermoso! Cuando hablamos de las redes sociales, usted aludía a la sustitución del trabajo humano por máquinas. La relación entre cuerpo y máquina es un aspecto central de "Palabras para una fábula", uno de los relatos de Historia de una mujer que caminó por la vida con zapatos de diseñador, de 2005, protagonizados por Nora García. El relato pone en escena una relación conflictiva entre su cuerpo y un mamógrafo. ¿Cómo ve la relación entre cuerpo y máquina en el ámbito de la medicina?

M.G.: La relación del cuerpo con las máquinas en el cuento que mencionas es que las máquinas son las que dan el diagnóstico. Ellas son las que revelan lo que tienes en el cuerpo. Pero también están vinculadas a la medicina y al ejercicio de la medicina. Y cómo lo trabajan los médicos y enfermeras que atienden a la gente a través de las máquinas. Cómo se deshumaniza absolutamente el cuerpo y cómo se deshumaniza al ser humano, minimizándolo, fragmentándolo de una manera muy artera y muy inconsciente para quien lo practica. En México, usamos demasiado el diminutivo, entonces para atenuar, para tratar del problema de la enfermedad, se trata al paciente como a un niño. Para todo se usa el diminutivo: "suba usted el bracito, ponga el pechito". Por un lado, te destruye como persona, te vuelves una persona que no tiene ninguna capacidad de decidir, estás en sus manos prácticamente. Estás en sus manos y te tratan como si fueras un niño de brazos o un niño que apenas empieza a hablar. Hay una condescendencia que se piensa que es benéfica pero que es denigrante para el enfermo. 
Ahora estamos en una época en que las máquinas se están convirtiendo en seres humanos por el avance de la robótica. Por ejemplo, en Japón se fabrican muñecas con una vagina para que los hombres las usen para saciar sus necesidades sexuales y no tengan que soportar a una esposa. Esa negación de cómo la robótica intensifica la violencia contra el cuerpo nos vuelve a todos hombres y mujeres desechables. Como de alguna manera ya lo habíamos visto en el Holocausto, donde se puso las máquinas al servicio de la destrucción a través de los hornos crematorios. Es una época terrible la que estamos viviendo y, además, aparentemente no tan violenta como los campos de concentración. Es más suave, pero más certera, más siniestra, diría.

F.L.: Entre las actividades fundamentales de Nora García está el caminar y desplazarse. Incluso Mario Bellatin escribió un texto muy gracioso en el que el Golem, que supuestamente usted hizo para ahuyentar a la "mujer de buen corazón" que alimenta a su perra Lola, destruye la ciudad y representa, a la vez, a Nora García y a Lola, la perra callejera. En La invención de lo cotidiano, Michel de Certeau señala que "el simple hecho de caminar por la ciudad modifica su cartografía”. ¿Cómo ve la relación entre espacio urbano y escritura? ¿Y cuál es la relación que existe entre su literatura y la ciudad de México?

M.G.: Justamente antier hicimos un experimento con lo del Golem, porque, cuando yo iba a cumplir 70 ańos, una época en que mi perra Lola vivía, 
Mario Bellatin y otro amigo se burlaron de mí y organizaron un festejo. Para ese festejo, construyeron un Golem que tenía que ver con mis zapatos y con mi perra y por eso está en este libro ${ }^{3}$.

Ahora, Mario tomó de ahí la idea del Golem e hicimos una cosa muy interesante vinculada con mi papá, que era un escritor, un poeta judío que escribía en una máquina de escribir con caracteres hebreos, una máquina que yo tengo. Sacamos la máquina y Mario escribía en una hoja de papel que tenía mi nombre impreso arriba. Entonces empezó a escribir con una cinta que está desde que mi papá se murió y que casi no pinta ya, pero perfora la página. Así quedó una página con caracteres únicos y vamos a hacer un montaje con eso, con el Golem, con fotografías de esa época, con un texto mío y con un texto de Mario, que va a salir en Chile ilustrado.

\section{F.L.: ¡Qué lindo!}

M.G.: Es muy bonito. Y justamente lo que usted está planteando, apenas antier decidimos hacerlo. Lo del espacio: yo no soy una deportista en absoluto. No sé nadar, no sé andar en bicicleta, no sé patinar, no sé hacer nada, saltar la cuerda ni nada, pero yo camino. Sé caminar. Camino. Y siempre he dicho, lo digo en Historia de una mujer..., que los pies son fundamentales, por eso me fijo tanto en los pies. Yo camino, camino y compro zapatos, camino,

3 La perra Lola aparece en algunos relatos de Historia de una mujer..., sobre todo en "Animal de dos semblantes". En este cuento, una mujer alimenta insistentemente a la perra de la protagonista, Nora García, colgando una bolsa con restos de carne en la puerta de su casa. Muy molesta, Nora piensa en diversas maneras de frenarla. 
camino y compro zapatos, camino, camino, veo la ciudad, voy a museos. Me encanta. Yo creo que una de mis lecturas más importantes es Georges Perec, por Je me souviens, ¿̇no? En muchísimos libros de Georges Perec, [está presente] el caminar por la ciudad, o sentarse en un lugar específico y observar qué pasa. Por ejemplo, estar sentada en un café, en un bistró, enfrente de la Iglesia de Saint-Sulpice y ver pasar a los autobuses y ver cómo la gente baja del autobús y empieza a descubrir una dinámica de la sociedad, de la ciudad y de las propias personas que están caminando por la ciudad. Entonces, lo más importante cuando uno viaja es caminar por la ciudad, cosa que ya casi no hago en México, porque ya no se puede caminar. Ayer de noche, estuvo aquí conmigo un amigo muy querido, él es como once años más chico que yo, pero recordamos cosas muy semejantes. Recordamos cómo cuando éramos jóvenes caminábamos por la ciudad; era una ciudad caminable y hoy es una ciudad totalmente incaminable. Coyoacán todavía es caminable, pero los barrios que yo caminaba de niña ya no son caminables. Ahora que ya estoy más vieja, camino menos. Por ejemplo, hablaba con una amiga hace rato, que vive en un barrio muy distante de la ciudad y, en diciembre, es imposible visitarla. Me puedo tomar un avión a Washington, pero no puedo ir a visitarla y está en la misma ciudad en donde yo vivo. La ciudad desde que yo era jovencita hasta ahora se ha modificado en tal grado que caminar se vuelve una especie de perversión. Hay un texto muy interesante en literatura, de Bradbury, es americano, una especie de distopía futurista. Habla de un personaje en Estados Unidos que camina y, mientras camina, a la policía le parece sospechoso y lo arrestan porque camina, porque ya 
la gente no camina. La imposición del automóvil fue una de las cosas más terribles que hizo Estados Unidos. Yo, alguna vez, he estado en Estados Unidos y no tenía coche en la ciudad y era terrible. Tomaba yo autobuses con los white trash $h^{4}$ los mexicanos y los negros. Yo era una "señorita" y tomaba autobuses donde la gente, hasta los más elementales, tienen coche, la gente no entendía. Estaba yo leyendo que se ha muerto George Bush, el padre, y la capilla ardiente estaba más o menos a veinte metros de donde estaba Trump y tomó un automóvil para ir. ¿̨No te parece una metáfora terrible de nuestra época y de Estados Unidos? Yo caminaba cuando era joven, y bella así de vestido y joyitas, a las 3 o 4 horas de la mańana por toda la ciudad y nunca me ha pasado nada, y hoy me da pánico que mi nieta, que tiene 24 ańos, ande sola por la ciudad, porque hay feminicidios, asaltos. O sea, la ciudad, que era el paradigma en el siglo XIX, la ciudad de los pasajes de Benjamin, o la ciudad de Thomas Mann, se ha vuelto como una enemiga. Y caminar se vuelve una especie de crimen, ¿no?

F.L.: ¿`Y los viajes? Para usted es fundamental viajar...

M.G.: Es otra forma de caminar, fundamental, y una forma de deshacer la rutina de desanquilosarse y eso es muy importante, porque la rutina te anquilosa. Te ayuda también, porque no puedo trabajar, no puedo escribir sin rutina, pero la rutina me anquilosa y viajar rompe la rutina y permite ver

4 De acuerdo con el Diccionario Collins, la expresión es un modo peyorativo de referirse a la gente blanca y pobre. 
otras cosas, otras ciudades, aunque con la globalización todas las ciudades se han asemejado mucho. El fascismo se ha globalizado, el consumo se ha globalizado, entonces te asusta. Yo iba a Berlín cuando era una especie de isla entre las dos Alemanias y era una ciudad muy viva, donde había boutiques en las que podías comprar cosas muy específicas, muy lindas. Ahora vuelves a Berlín y está Christian Dior, Yves Saint-Laurent, no sé, vas de una ciudad a otra y todas son iguales, las mismas calles, como en Polanco, aquí en México, o me imagino que en São Paulo. Entonces vemos como todo se homogeneiza, como el terror a la heterogeneidad se vuelve una especie de tabú: no hay que ser distinto, hay que ser idéntico, por eso la globalización es tan perversa. 
